Vol 1, pp 84-95, April 2017 - ISSN 2561-1666

\title{
Anglophone culture, Francophone culture, family behaviours, and childhood obesity in Sudbury, Ontario
}

\author{
J. M. Geist, L. Tremblay, S. Dorman, C. Rinaldi
}

J. M. Geist, MSc(c)

Student, School of Rural and Northern Health

Laurentian University

jgeist@laurentian.ca

L. Tremblay, $\mathrm{PhD}$

Professor, School of Human Kinetics

Laurentian University

ltremblay@laurentian.ca

S. Dorman, $\mathrm{PhD}$

Associate Professor, School of Human Kinetics

Laurentian University

sdorman@laurentian.ca

C. Rinaldi, $\mathrm{PhD}$

Professor, Educational Psychology

University of Alberta

christina.rinaldi@ualberta.ca 
Diversity of Research in Health Journal / Revue de la Diversité de la Recherche en Santé

Vol 1, pp 84-95, April 2017

\begin{abstract}
In general, Francophones in Ontario are more likely than their Anglophone counterparts to suffer from overweight and obesity. It has also been established that Francophones, Canada-wide, eat fewer daily servings of fruits and vegetables than Anglophones and tend to consume more kilocalories from fat (Batal et al., 2013). Despite these trends, comparative investigations amongst Francophone and Anglophone children in Ontario have not been completed. Therefore, the purpose of this literature review will be to investigate research evidence regarding Francophone children in Ontario and whether they are more likely or less likely to suffer from overweight or obesity than Anglophone children in Ontario. In addition, we will examine research on cultural factors that may be different between the two linguistic groups and which may contribute to the prevalence of obesity. This literature review will present an overview of childhood obesity in Northern Ontario and Francophone and Anglophone culture as well as identify the gaps within the literature for that require further research attention.
\end{abstract}

Keywords: culture, childhood obesity, Sudbury

\title{
Résumé
}

En général, les francophones de l'Ontario sont plus susceptibles que leurs homologues anglophones de souffrir de surpoids et d'obésité. Il a également été établi que les francophones, à l'échelle du Canada, mangent moins de portions quotidiennes de fruits et de légumes que les anglophones et ont tendance à consommer plus de kilocalories en gras (Batal et al., 2013). Malgré ces tendances, les enquêtes comparatives menées par des enfants francophones et anglophones en Ontario n'ont pas été complétées. Par conséquent, le but de cette revue de la littérature sera d'enquêter sur les résultats de la recherche concernant les enfants francophones en Ontario et s'ils sont plus susceptibles ou moins susceptibles d'être en surpoids ou d'obésité que les enfants anglophones en Ontario. En outre, nous examinerons la recherche sur les facteurs culturels qui peuvent être différents entre les deux groupes linguistiques et qui peuvent contribuer à la prévalence de l'obésité. Cette revue de la littérature présentera un aperçu de l'obésité infantile dans le Nord de l'Ontario et de la culture francophone et anglophone, ainsi que d'identifier les lacunes de la littérature qui nécessitent une attention accrue à la recherche.

Mots-clés: culture, obésité infantile, Sudbury 
Diversity of Research in Health Journal / Revue de la Diversité de la Recherche en Santé

Vol 1, pp 84-95, April 2017

\section{Obesity As A Disease}

In 1978, $15 \%$ of Canadian children aged 2- to 17-years-old were classified as overweight or obese (Statistics Canada, 2011). Thirty years later, the Canadian Health Measures Survey reported that nearly a third of Canadian children, in the same demographic, were classified as overweight or obese (Statistics Canada, 2011). Childhood obesity continues to be a major health concern for Canadians. Childhood obesity has been correlated with type 2 diabetes, cardiovascular disease, hypertension, stroke, gallbladder disease, some types of cancer, osteoarthritis and psychosocial problems in adulthood (Statistics Canada, 2011). Children suffering from obesity are also more likely to experience low self-esteem, and behavioural, psychological, and psychiatric problems (Reilly et al., 2003). There are also increased health issues with high blood pressure, dyslipidemia, abnormalities in left ventricle mass/function, abnormalities in endothelial function, hyperinsulinemia/insulin resistance, and high LDL cholesterol levels (Reilly et al., 2003). There is also evidence that asthma, type 1 diabetes, and lowgrade systemic inflammation are more likely to develop in obese children (Reilly et al., 2003). Many long-term effects of obesity exist, including increased early mortality risk, and increased cardiovascular morbidity (Reilly et al., 2003). These negative health implications justify the need for further research on childhood obesity.

\section{Defining and Measuring Childhood Obesity}

Considering the myriad of negative health implications that accompany childhood obesity, it is important to understand how obesity is defined in children. Obesity is generally defined as excess body fat (Taubes, 2013). The most accurate method of measurement is to measure exact body fat percentage with a CT scan, followed by hydrostatic tank, bod-pod measurement, skinfold measures, and electrical impedance (Abu Khaled, et al., 1988; Biaggi et al., 1999; Durnin \& Rahaman, 1967; Taubes, 2013; Tokunaga, Matsuzawa, Ishikawa, \& Tarui, 1982; Vescovi, et al., 2001). These methods are not ideal for larger scale research studies because they require complex equipment, travel to facilities containing the equipment, or are moderately invasive (Tokunaga et al., 1982 Biaggi et al., 1999; Vescovi, et al., 2001; Durnin \& Rahaman, 1967). Because of these reasons, a reference value was developed to easily and quickly quantify the weight status of an individual (Kiess et al., 2004). This reference value is called Body Mass Index (BMI), and it is calculated by dividing the mass of an individual in kilograms by the squared height of the individual in meters. For example, an individual weighing $70 \mathrm{~kg}$ and standing at $1.73 \mathrm{~m}$ would have a BMI value of 23.4. This system was first developed to classify weight density (termed "fatness" in the original article) of 7424 men across multiple cohorts from different countries (Keys et al., 1972). Researchers have continued to use this index system, and increased BMI values have since been linked with increased risk for type 2 diabetes, cardiovascular disease, and some forms of cancer (Reilly et al., 2003). Because of its ease of use and effectiveness in the aforementioned disease risk prediction, it is commonly used to describe individual weight status (Keiss et al., 2004). In general, adults with a BMI rating of $25 \mathrm{~kg} / \mathrm{m}^{2}$ or over are considered overweight; adults with a BMI rating of $30 \mathrm{~kg} / \mathrm{m}^{2}$ or more are classified as obese (Marshall et al., 2004).

Unfortunately, it becomes difficult to classify a child's weight status using the BMI system. In their growing years, children experience fluctuations in BMI at different 
Diversity of Research in Health Journal / Revue de la Diversité de la Recherche en Santé Vol 1, pp 84-95, April 2017

rates and different times in their development, making it impossible to define a set BMI value to represent overweight or obesity (Marshall et al., 2004). As such, three different organizations have devised growth reference charts to set BMI cutoff points according to age and sex (Marshall et al., 2004): The International Obesity Task Force (IOTF), Center for Disease Control (CDC), and the World Health Organization (WHO) all developed growth reference charts based on different goals and different target populations. Whereas the WHO based its reference calculations on a prescribed "desired standard", and the IOTF developed its reference to have international applicability, the CDC constructed its reference guide off a real American reference population (Kiess et al., 2004). The CDC guidelines were developed from multiple cycles of census information spanning 31 years (Shields \& Tremblay, 2010). The CDC guidelines, when used with Canadian census information, estimate a median level of obesity as compared with the WHO guidelines and the IOTF guidelines (Shields \& Tremblay, 2010). As such, Canadian clinical guidelines recommend the use of CDC guidelines for screening children and adolescents for overweight and obesity (Shields \& Tremblay, 2010). Within Ontario, physicians are only recommended to screen for childhood overweight and obesity using the CDC guidelines (Shields \& Tremblay, 2010).

When using BMI to classify an individual as overweight or obese, a correct and accurate measure of individual height and weight is required. Two popular methods of determining participant height and weight are objective (measured) and subjective (selfreported; Gorber et al., 2007). In objective measurement, height and weight is measured at the time of survey, and these results are generally accepted to be the more accurate method (Gorber et al., 2007); however, compared to self report, it is more time consuming, and harder to implement in larger studies (Gorber et al., 2007). Therefore, self-reported height and weight is the more common method for determining BMI (Gorber et al., 2007). It is recognized that both men and women tend to underestimate their weight and overestimate their height, effectively causing an underestimation of BMI (Gorber et al., 2007). This trend is amplified in people already suffering from overweight or obesity (Gorber et al., 2007). In children, similar results are seen: both the child and their parents/guardians underestimate body weight (Chaimovitz et al., 2008). Interestingly, physicians also have a tendency to underestimate children's weight (Chaimovitz et al., 2008). In order to accurately describe the weight status of children and work towards successfully identifying the prevalence of overweight and obese children in Ontario, it may be necessary to survey children by physically measuring them.

\section{Factors Contributing to Obesity}

After defining what childhood overweight and obesity is, it becomes important to identify and explore some of the factors responsible for its development. Obesity is physiologically defined as a net, positive energy imbalance: that is, a state accomplished by either consuming too many calories or expending too few calories by way of decreased physical activity, or both (Taubes, 2013). The factors contributing to enhanced kilocalorie consumption and decreasing physical activity are complex and multifactorial.

Nationally, there is a trend towards nutrient-poor diets in Canadian children (Roblin, 2007). Since the 1990s, children have been consuming less milk, vegetables, whole grain bread products, and eggs (Roblin, 2007). This trend occurred with a simultaneous increase in the consumption of fruits, fruit juices, carbonated soft drinks, 
Diversity of Research in Health Journal / Revue de la Diversité de la Recherche en Santé Vol 1, pp 84-95, April 2017

salty snacks, poultry, and cheese (Roblin, 2007). The vast majority of Canadian children do not eat enough servings of fruits and vegetables (62\% of girls, $69 \%$ of boys), and dairy products (83\% of girls, 61\% of boys) (Roblin, 2007). The increased consumption of sugary soft drinks is also of concern as it is correlated with increased risk of obesity in children (Roblin, 2007). Of equal concern is fast food restaurants and eating out of the home. Since the 1970s, the portion sizes of fast food and restaurant meals have risen, possibly contributing to overeating (Roblin, 2007). Within the home, the reported incidence of commercially prepared meals as opposed to home-prepared meals eaten per week increased from 2.48 in 1978 to 2.77 in 2000 (Kant \& Graubard, 2004). This tendency to eat out adds to a poorer diet because of the tendency for commerciallyprepared meals to contain high numbers of kilocalories, fat, and salt (Kant \& Graubard, 2004).

There is also evidence that today, children are engaging in decreasing levels of physical activity compared to previous generations. A study done by Tomkinson, Leger, Olds, and Cazorla (2003) identified a significant decrease in children's performance on the $20 \mathrm{~m}$ shuttle run test (otherwise known as the Beep Test) from 1980 to 2000. The overall increase in sedentary behaviour may also be playing a role in the prevalence of childhood obesity. Tremblay et al. (2011) reported that just two hours of sedentary behaviour per day was significantly correlated with unfavourable body composition in school-aged children. This compilation of evidence suggests that children may be currently maintaining a worse diet and engage in less physical activity than children 30 years ago.

\section{Examination of Risk factors contributing to Childhood Obesity}

It is important to explore why these trends in poorer diet and less physical activity are seen. Most researchers agree that childhood obesity is a result of the complex interaction of a plethora of factors beyond poor eating habits and reduced physical activity (Kant \& Graubard, 2004; Marshall et al., 2004; Reilly et al., 2003; Tremblay et al., 2011). Factors that are believed to contribute to the increased prevalence of obesity in children are discussed below.

Screen-time: A meta-analysis completed by Marshall et al. (2004) found that a review of the data up until 2004 indicated a small but significant positive correlation between hours of TV watched and BMI index of children. These researchers suggest that these hours spent watching TV displaced hours spent engaging in physical activity. The Quebec Longitudinal Study of Child Development found that increased TV time correlated with less healthy eating habits and higher BMIs of children (the results were only statistically significant for girls, but the same trends were seen in boys; Tremblay \& Rinaldi, 2010). Of even more interest is the practice of television viewing during family meals (Fitzpatrick et al., 2007). Studies completed by Fitzpatrick et al. (2007) explored the use of family mealtimes as a promoter for healthy eating in children, and if television viewing during those mealtimes negates those positive effects. They found that children between the ages of 1 and 4 ate more servings of fruits and vegetables, and drank more milk when they ate dinner with the family. However, these effects were reversed when the family viewed television during those family meals.

Family interactions and dynamics: Another factor that is correlated with overweight and obesity in children are negative family interactions that occur during 
Diversity of Research in Health Journal / Revue de la Diversité de la Recherche en Santé Vol 1, pp 84-95, April 2017

mealtimes (Orrell-Valente et al., 2007). Negative family interactions, defined as parents dishing out food for their children without the children's input on quantity, forcing the children to stay at the table until they complete their meal, not allowing the children dessert until their plate has been finished, and hurrying children to eat were correlated with increased consumption of food and increased weight-to-height ratios in the children of those families (Orrell-Valente et al., 2007). In addition, general negative family interactions (outside of family mealtime) and family stress have been correlated with higher weight in children (Repetti, Robles, \& Reynolds, 2014). Specifically, authoritarian parenting techniques (harsh and controlling), familial disorganization, parental neglect, lack of emotional support, lack of warm and nurturing environment, hostile interactions, indulgent/permissive behaviour, and inconsistent discipline were correlated with increased prevalence of obesity in children (Berge et al., 2014; Garasky et al., 2009; Gibson et al., 2007; \& Repetti, Robles, \& Reynolds, 2014). This is suggested to be due to the children losing the ability to self-regulate because of chronic stressful environments (Repetti et al., 2014). Controlling feeding strategies employed by parents, like pressure, to finish a plate or pressure to stop eating were associated with unhealthy weight status (Tremblay et al., 2012). In fact, increased family conflict is thought to increase speed of eating in order to avoid the mealtime in its totality (Tremblay, Rinaldi, Cimon-Lambert, \& Lariviere, 2012). It is even suggested that parents may use fast food as a way to expedite mealtimes, offering an explanation as to why families with more conflict raise heavier children (Tremblay et al., 2012).

Family size and structure also plays a role in childhood obesity prevalence. Children from single-parent families, or children without any siblings were more likely to develop obesity, reported Chen and Escarce (2010). Of similar concern is the tendency for obese parents to raise obese children. Children are more likely to develop obesity by the age of 10 if one or both of their parents is obese (Whitaker et al., 1997).

Socioeconomic status: One factor that must be considered as a determinant of obesity is the tendency for individuals with higher socioeconomic status to have lower BMIs and lower rates of overweight and obesity (in developed countries; McLaren, 2007). This trend is more pronounced in women (McLaren, 2007). For children, however, the association is not so clear (Shrewsbury \& Wardle, 2008). In general, this trend is reflected in child populations in developed countries (Shrewsbury \& Wardle, 2008). To elaborate, children of parents who have high socioeconomic status are generally less likely to be overweight/obese than those of low socioeconomic status parents. This is another important consideration when examining risk factors and prevalence of childhood obesity.

Official language group: In Ontario, one important risk factor for adult obesity (and the main focus of this review) is belonging to the Francophone linguistic group. In Ontario, minority Francophones are more overweight and obese than their majority Anglophone counterparts (Deuxieme rapport..., 2005). However, it is unclear if belonging to the Francophone linguistic group is correlated with obesity in children because the Canadian Community Health Survey cycles survey individuals aged 12 and up, and the Statistics Canada household census surveys individuals aged 17 and up. As such, overweight and obesity rates for Francophone and Anglophone children in Ontario have not been established. 
Diversity of Research in Health Journal / Revue de la Diversité de la Recherche en Santé

Vol 1, pp 84-95, April 2017

\section{Importance of Studying Obesity in Francophones and Anglophones living in a Northern Ontario City}

Sudbury, Ontario was determined to be the second most obese metropolitan area in all of Canada in 2014 (Sudbury second-most obese city..., 2014). This statistic is concerning because of the clear negative health implications associated with excess weight outlined in the introduction. Because of this high obesity rate in Sudbury, there is a clear need for more obesity research in Sudbury.

One special consideration specific to the Sudbury population is the long-standing Francophone heritage in the area. Traditionally, Statistics Canada defines a Francophone as an individual whose mother tongue is French and still understands the French language at the time of survey. Sudbury has the largest proportion of French-speaking people to English speaking people in all of Ontario (26.9\% of Sudbury is French speaking, whereas $3.9 \%$ of Ontario is French speaking as a whole; Statistics Canada, 2006). Minority Francophone populations living within Ontario historically self-report lower levels of health, endure higher rates of heart disease, are more likely to smoke, have lower intakes of fruits and vegetables, have higher rates of tobacco and alcohol use, are less likely to seek a dentist, and report a poor sense of community belonging (Picard \& Allaire, 2005). Minority Francophones in Ontario are also more likely to have a lower socioeconomic status (mostly attributed to the fact that the general Francophone population in Ontario is older than the general population; Picard \& Allaire, 2005), which is futher correlated with increased rates of overweight and obesity (Gagnon-Arpin, Makvandi, Imbeault, BATAL, \& Bouchard, 2013). And, as mentioned before, minority Francophone populations in Ontario also suffer from higher rates of overweight and obesity when compared with Anglophone populations, further adding to the existing disparities in the health statuses of Francophones.

There has been a long-standing call for the rectification of certain Francophone health inequalities (Picard \& Allaire, 2005). The need for culturally sensitive and appropriate health care services for Francophones in Ontario has been recognized by the Ministry of Health and Francophone networks alike (Picard \& Allaire, 2005). Exploring the weight statuses of Francophone and Anglophone children in Sudbury, Ontario will help health professionals and policy makers to identify key risk areas requiring more attention, and identify strategies to remediate any issues found.

That taken into consideration, the aim of this literature review cannot be forgotten: exploring the need for Sudbury-specific data on Francophone and Anglophone child weight statuses. The combination of Sudbury's unique obesity issue, the increased prevalence of overweight and obesity in Francophone populations in Ontario, and the high proportion of Francophones in Sudbury fully warrant research on childhood obesity rates within the city.

\section{Culture as a Determinant in Obesity}

There is some evidence that suggests culture as a social determinant of health (Social Determinants of Health, 2016). This next section explains how culture can serve as an explanatory framework for why there may be differing rates of overweight and obesity in Francophone and Anglophone Sudbury children. 
Diversity of Research in Health Journal / Revue de la Diversité de la Recherche en Santé Vol 1, pp 84-95, April 2017

The hypothesis of cultural differences' impact on prevalence of childhood obesity in Francophones and Anglophones has come from the inclusion of culture as a social determinant of health (Social Determinants of Health, 2016). In this sense, groups of people sharing a culture can experience health inequalities because of marginalization, lack of culturally appropriate health care, lack of health care in their language, and devaluation of language (Social Determinants of Health, 2016). One issue often experienced by Francophones in Ontario is lack of health services in their own language, which leads to poor patient health outcomes (Drouin \& Rivet, 2003). Even though Ontario has the largest population of Francophones outside of Quebec, they still remain a minority population, and have a chronic lack of health care services in French (Drouin \& Rivet, 2003). There is an even greater lack of language-appropriate health care in communities where there are large numbers of Francophones (i.e. Sudbury; Drouin \& Rivet, 2003). With this health inequality taken into consideration, culture becomes a relevant health determinant. Not only are Francophones in Ontario less healthy in correlation with the language they speak, they are also more overweight and obese than their Anglophone counterparts (Picard \& Allaire, 2005). Culture must be considered as a determinant in this ill-health.

Race and ethnicity are socially constructed concepts used to group people on the basis of shared characteristics (Caprio, Daniels, Drewnowski, Kaufman, Palinkas, Rosenbloom, \& Schwimmer, 2008). Although race and ethnicity are often based on characteristics like genes or skin colour, shared language can also categorize culture (Caprio et al., 2008). Because of this definition of culture, it is important to remember the Francophne and Anglophone classification not only as language designations, but as cultural designations as well. There is an understanding that culture plays a pivotal role in how (or if) an individual engages in health-promoting behaviours (like diet and exercise; Caprio et al., 2008). Cultural values and beliefs can push certain ethnicities or language groups to certain health behaviours - for example, first-generation Latino and Asian adolescents in the United States have been found to consume more fruits and vegetables and less carbonated drinks than the white population (Caprio et al., 2008). Also within the United States, different ethnic groups experience different rates of childhood obesity. For example, childhood obesity rates are higher in Hispanic, Latino, African American, Mexican American, and Native American populations when compared to the majority white population (Caprio et al., 2008). This difference in childhood obesity rates is thought to be due to a complex and ill-understood interaction between genetics, culture, socioeconomic status, and environment (Caprio et al., 2008). In treating the Francophone and Anglophone language groups as cultural designations, it allows us to explore culture as an important interacting factor with childhood obesity.

In order to study culture as one of the determinants of childhood obesity, a way of studying and/or classifying culture must be established first. Because family is at the heart of culture, studying the family and its systems is an effective way of studying culture (Bryant et al., 2004). The family is the main instrument in which children become acculturated; parents are often highly involved in the early years of children. Giving them ample opportunity to pass on the ideals, values, and beliefs of the culture (Bruss, Morris, Dannison \& Orbe, 2005). One of the most prominent ways of cultural transmission is through feeding and mealtimes, as so much of the family's time is devoted to these (Bruss et al., 2005). 
Diversity of Research in Health Journal / Revue de la Diversité de la Recherche en Santé Vol 1, pp 84-95, April 2017

Culture determines what parents deem as safe, accessible, nutritious, convenient, and desirable food for their children (Bryant et al., 2004). Similarly, food practices (for example, acceptance of and engagement in a traditional "family dinner") are largely determined by culture (Bryant et al., 2004). These are the factors that can be hypothesized to have an effect on prevalence of obesity in Francophone and Anglophone children. In treating their language designation as a cultural designation, it becomes relevant to examine Francophone and Anglophone eating practices as products of those different cultures, suggesting a tangible and meaningful difference that can potentially provide a better narrative as to why Francophones may experience greater rates of overweight and obesity than Anglophones living in Ontario.

\section{Conclusion}

Childhood obesity can be likened to a plethora of factors including increased television watching during mealtimes (Fitzpatrick et al, 2007), negative family interactions during mealtimes (Orrell-Valente et al., 2007), authoritarian parenting styles (Repetti et al., 2014), family size and structure (Chen \& Escarce, 2010), socioeconomic status (McLaren, 2007), and being a minority Francophone (Deuxieme rapport..., 2005).

Of most importance to this review is the finding that Francophone populations in Ontario are more overweight and obese than their Anglophone counterparts (Deuxieme rapport..., 2005). Within Sudbury, Ontario, the population consists of 26.9\% individuals with French as their mother tongue. Sudbury also has one of the highest obesity rates across the country (Sudbury second-most obese city..., 2014). There is a clear need for more obesity research in Sudbury, taking into account the vulnerable Francophone populations.

Bearing that in mind, there is also need for child-specific data. Are Francophone children more overweight/obese than their Anglophone counterparts? More research is necessary to set out to compile preliminary evidence to either support or refute this argument.

More research is also needed to discover differences between the two linguistic groups that could lead to the increased prevalence of overweight and obesity in Francophones or Anglophones. In this, we need to uncover if there is a specific Francophone or Anglophone culture that fosters certain family behaviours that are correlated with overweight/obesity in children, and what, if any, family factors contributed to increased childhood overweight/obesity in Francophone/Anglophone families.

Proposed new research from this review would add to our body of knowledge of childhood obesity in Sudbury and across official language groups. Because of Sudbury's unique situation (having such a high rate of overweight/obesity, and such a large proportion of Francophones; Batal et al., 2013), there is a call for region-specific evidence to rectify the true state of obesity across Francophone and Anglophone children in Sudbury. Sudbury is the largest functioning metropolitan area in Northern Ontario in regional services such as retail, healthcare, mining, education, and government services (Hall \& Donald, 2009). It is the home to innovative mining technologies, a revolutionary medical school, creative and influential film and digital animation companies, a strong presence of natural environment within city boundaries, and essential hospital services serving much farther North (Hall \& Donald, 2009). The healthy functioning of the 
Diversity of Research in Health Journal / Revue de la Diversité de la Recherche en Santé

Vol 1, pp 84-95, April 2017

individuals that make up Sudbury is important to the successful functioning of the city. Our study proposes to describe the general state of childhood obesity and overweight in the two official language groups in Sudbury, Ontario. Hopefully, the data that our study provides will not only further explain the state of the overweight and obesity epidemic of children in Sudbury, but also identify high-risk groups requiring attention if they exist, informing policy makers of the needs of the community. The data that this study aims to produce holds promise of informing intervention strategies, further rectifying the health needs of both our official language groups.

\section{References}

Abu Khaled, M., McCutcheon, M. J., Reddy, S., Pearman, P. L., Hunter, G. R., Weinsier, R. L. (1988). Electrical impedance in assessing human body composition: the BIA method. The American Society for Clinical Nutrition, 47(5), 789-792.

Batal, M., Makvandi, E., Imbeault, P., Gagnon-Arpin, I., Grenier, J., Chomienne, M. H., \& Bouchard, L. (2013). Comparison of dietary intake between francophones and anglophones in canada: Data From CCHS 2.2. Canadian Journal of Public Health / Revue Canadienne De Santé Publique, 104(6), S31-S38. Retrieved from http://www.jstor.org/stable/canajpublheal.104.6.0s31

Biaggi, R. R., Vollman, M. W., Nies, M. A., Brener, C. E., Flakoll, P. J., Levenhagen, D. K., Sun, M., Karabulut, Z., \& Chen, K. Y. (1999). Comparison of airdisplacement plethysmography with hydrostatic weighing and bioelectrical impedance analysis for the assessment of body composition in healthy adults. American Society of Clinical Nutrition, 105(1), 898-903.

Bruss, M. B., Morris, J. R., Dannison, L. L., Orbe, M. P. (2005). Food, culture, and the family: Exploring the coordinated management of meaning regarding childhood obesity. Health Communication, 18(2), 155-175.

Bryant, C.A., K Dewalt, A. Courtney, and J. Schwartz. (2004). The cultural feast: An introduction to food and culture, Second Edition. Canada: Wadsworth.

Caprio, S., Daniels, S. R., Drewnowski, A., Kaufman, F. R., Palinkas, L. A., Rosenbloom, A. L., Schwimmer, J. B. (2008). Influence of race, ethnicity, and culture on childhood obesity: Implications for prevention and treatment. Obesity, 16(12), 2566-2577.

CDC. (2016, December 2). Division of nutrition, physical activity, and obesity (DNPAO). Retrieved January 10, 2017, from Centers for Disease Control and Prevention, https://www.cdc.gov/nccdphp/dnpao/

Chaimovitz, R., Issenman, R., Moffat, T., \& Persad, R. (2008). Body perception: Do parents, their children, and their children's physicians perceive body image differently? Journal of Pediatric Gastroenterology and Nutrition, 47, 76-80.

Durnin, J. V. G. A., \& Rahaman, M. W. (1967). The assessment of the amount of fat in the human body from measurements of skinfold thickness. The British Journal of Nutrition, 21(3), 681-689.

Deuxième rapport sur la santé des francophones de l'Ontario. Institut francoontarien de l'Université Laurentienne, en collaboration avec le Programme de recherche, d'éducation et de développement en santé publique, 2005;159.

Fawcett, K. A., Barosso, I. (2010). The genetics of obesity: FTO leads the way. Trends in Genetics, 26(6), 266-274. 
Diversity of Research in Health Journal / Revue de la Diversité de la Recherche en Santé

Vol 1, pp 84-95, April 2017

Gagnon-Arpin, L., Makvandi, E., Imbeault, P., Batal, M., Bouchard, L. (2013). Le surplus de poids chez les francophones et les anglophones. Revue Canadienne de Sante Publique, 104(6), S21-S25.

Gorber, S. C., Tremblay, M., Moher, D., \& Gorber, B. (2007). A comparison of direct vs. self-reported measures for assessing height, weight, and Body Mass Index: A systematic review. Obesity Reviews, 8(4), 307-326.

Hall, H. \& Donald, B. (2009). Innovation and creativity on the periphery: Challenges and opportunities in Northern Ontario. Ontario in the Creative Stages, 1-33.

Kant, A. K., Graubard, B. I. (2004). Eating out America, 1987-2000: trends and nutritional correlates. Preventive Medicine, 38, 243-249.

Keiss, W., Marcus, C., Wabitsch, M. (2004). Obesity in childhood and adolescence. Pediatric and Adolescent Medicine, 9. Basel: Karger.

Marshall, S. J., Biddle, S. J. H., Gorely, T., Cameron, N., Murdey, I. (2004). Relationships between media use, body fatness, and physical activity in children and youth: a meta-analysis. International Journal of Obesity, 28, 1238-1246.

McLaren, L. (2007). Socioeconomic status and obesity. Epidemiologic Reviews, 29(2007), 29- 48.

Overweight and obesity in children and adolescents: Results from the 2009 to 2011 Canadian Health Measures Survey. (2015, July 17). Retrieved December 3, 2016, from Statistics Canada, http://www.statcan.gc.ca/pub/82-003x/2012003/article/11706-eng.htm

Picard, L., \& Allaire, G. (2005). Second report on the health of Francophones in Ontario. Sudbury, ON: Public Health Research, Education and Development Program; 2005. Available from: www.opha.on.ca/resources/docs/HealthofFrancophonesEN.pdf. Accessed 2012 Nov 5.

Reilly, J. J., Methven, E., McDowell, Z. C., Hacking, B., Alexander, D., \& Stewart, L. (2003). Health consequences of obesity. Archives of Diseases in Childhood, $88(9), 748-752$.

Roblin, L. (2007). Childhood obesity: food, nutrient, and eating-habit trends and influences. Applied Physiology, Nutrition, and Metabolism, 32(2007), 635-645.

Shields, M., Tremblay, M. S. (2010). Canadian childhood obesity estimates based on WHO, IOTF, and CDC cut-points. International Journal of Pediatric Obesity, 5, 265-273.

Retrieved

from http://journals1.scholarsportal.info.librweb.laurentian.ca/pdf/17477166/v05i0003/ 265ccoebowiacc.xml

Social determinants of health. (2016, September 26). Public Health Agency of Canada. Retrieved January 10, 2017, from http://cbpp-pcpe.phac-aspc.gc.ca/public-healthtopics/social-determinants-of-health/

Statistics Canada. (2006). Health Reports, volume 17, number 3. http://publications.gc.ca/Collection-R/Statcan/82-003-XIE/82003XIE2005003.pdf\#page $=27$

Taubes, G. (2013). The science of obesity: what do we really know about what makes us fat? An essay by Gary Taubes. British Medical Journal, 2013, 346.

Tokunaga, K., Matsuzawa, Y., Ishikawa, K., \& Tarui, S. (1982). A novel technique for the determination of body fat by computed tomography. International Journal of Obesity, 7.5(1982), 437-445. 
Diversity of Research in Health Journal / Revue de la Diversité de la Recherche en Santé

Vol 1, pp 84-95, April 2017

Tremblay, M. S., LeBlanc, A. G., Kho, M. E., Saunders, T. J., Larouche, R., Colley, R. C., Goldfield, G., Gorber, S. C. (2011). Systematic review of sedentary behaviour and health indicators in school-aged children and youth. International Journal of Behavioural Nutrition and Physical Activity, 8(1), 1.

Tremblay, L., Rinaldi, C. M. (2010). The prediction of preschool children's weight from family environment factors: gender-linked difference. Eating Behaviors, 11(2010), 266-275.

Vescovi, J. D., Zimmerman, S. L., Miller, W. C., Hildebrandt, L., Hammer, R. L., Fernhall, B. (2001). Evaluation of BOD POD for estimating percentage body fat in a heterogenous group of adult humans. European Journal of Applied Physiology, 85(3), 326-332.

(2014, October 20). Sudbury second-most obese city in Canada: Stats Can. CBC News. Retrieved from http://www.cbc.ca/news/canada/sudbury/sudbury-second-mostobese-city-in-canada-stats-can-1.2805270 